\title{
International Trade and Income Distribution
}

\author{
Xiaokai Yang and Dingsheng Zhang \\ CID Working Paper No. 18 \\ June 1999
}

(c) Copyright 1999 Xiaokai Yang, Dingsheng Zhang, and the President and Fellows of Harvard College

\section{Working Papers Center for International Development at Harvard University}




\title{
International Trade and Income Distribution
}

\author{
Xiaokai Yang and Dingsheng Zhang*
}

\begin{abstract}
This paper applies the inframarginal analysis, which is a combination of marginal and total costbenefit analysis, to investigate the relationship between division of labor, the extent of the market, productivity, and inequality of income distribution. The model with transaction costs and exogenous and endogenous comparative advantages shows that as transaction conditions are improved, the general equilibrium discontinuously jumps from autarky to partial division of labor with a dual structure, then to the complete division of labor where dual structure disappears. In this process different groups of individuals with different transaction conditions get involved in a certain level of division of labor at different stages of development. As the leading group gets involved in a higher level of division of level, leaving others behind dual structure emerges and inequality increases. As latecomers catch up dual structure disappears and inequality declines. When the leader goes to an even higher level of specialization, dual structure occurs and inequality increases again. Inequality decreases again as the latecomers catch up. Hence, the equilibrium degree of inequality fluctuates in this development process. The relationship between inequality and productivity is neither monotonically positive nor monotonically negative. It might not be of inverted U-curve. The key driving force of economic development and trade is improvement in transaction conditions.
\end{abstract}

JEL codes: D30, F10, O10.

Key words: Income distribution, division of labor, dual structure, economic development

Xiaokai Yang is a Research Fellow at the Center for International Development and a Reader at the Department of Economics, Monash University, Australia. His research interests include equilibrium network of division of labor, endogenous comparative advantages, inframarginal analysis of patterns of trade and economic development.

Dingsheng Zhang is Professor of Research Center of Economics, Wuhan University. His current research interests include dual structure in economic development, economic development and income distribution, equilibrium models of monopolistic competition, trade pattern and development strategies.

\footnotetext{
*We are grateful to Guangzhen Sun, Lin Zhou, Meng-Chun Liu for helpful discussion and to the Australian Research Council for financial support (Large Grant A79602713) is gratefully acknowledged. We are solely responsible for the remaining errors.
} 


\title{
International Trade and Income Distribution
}

\author{
Xiaokai Yang and Dingsheng Zhang
}

\section{Introduction}

The purpose of this paper is twofold. First, we develop a general equilibrium model with endogenous specialization to show that the relationship between economic development and inequality of income distribution is neither monotonic nor an inverted U-curve. Second, we use the general equilibrium model to investigate interdependence between the extent of the market, the level of division of labor, productivity, and the degree of inequality of income distribution.

Let us motivate the two tasks one by one. Krugman $(1995,1996)$ and Krugman and Venables (1995) vividly document the fact that the relationship between economic development and income distribution comes to the focus of public concern in the 1970s and 1990s. But this is always a controversial issue in economic literature. Some models and theories are developed, with empirical evidence sometimes, to show that there is a positive correlation between economic development and inequality of income distribution (Banerjee and Newman, 1993, Lewis, 1955, Palma, 1978, Li and Zou, 1998, for instance). Other models are developed, with empirical evidence sometime, to show that there is a negative correlation between inequality and international trade, which relates to economic development (Alesina and Rodrik, 1994, Galor and Zeira, 1993, Thompson, 1995 and Fei, Ranis, and Kuo, 1979, Frank, 1977, Balassa, 1986, for instance).

Not only data from developing and newly industrialized countries are contradictory, but also data from developed countries generate more controversies. Kuznetz (1955) proposed the hypothesis of inverted U-curve of the relationship between inequality and per capita income and 
provided some support for it from US data. Krugman and Venables (1995) use a general equilibrium model with global economies of scale to predict such an inverted U-curve of inequality. Greenwood and Jovanovic (1990) use a dynamic equilibrium model to predict the inverted U-curve. Some theories and data show that there is a negative or insignificant correlation between trade or development and inequality in the developed country (see, for instance, Krugman and Lawrence, 1994 and Katz and Murphy, 1992). Others show a positive correlation between trade and inequality in the developed country (see, for instance, Grossman, 1998, Murphy and Welch, 1991, Borjas, Freeman, and Katz, 1992, Karoly and Klerman, 1994, Sachs and Shatz, 1995 ). ${ }^{1}$ But Ram (1997) provides new empirical evidence for an uninverted-U pattern in the developed countries, taking into account of data since World War II. Jones (1998, p. 65) also shows that the ratio of GDP per worker in the $5^{\text {th }}$-richest country to GDP per worker in the $5^{\text {th }}$-poorest country fluctuated from 1960 to 1990.

The controversy and new evidences call for new models and theories that can resolve it. In the current paper, we develop a general equilibrium model to show that the relationship between inequality and trade that relates to economic development is neither monotonic nor an inverted U-curve.

In our general equilibrium model of endogenous specialization, economic development is described as an evolutionary process of division of labor that is driven by improvements in transaction conditions. Because of differences in transaction conditions between countries and between different groups of residents in the same country, those individuals with better transaction conditions will be involved in the division of labor and related trade before others are. Inequality increases because of the dual structure. As latecomers catch up, the dual structure

\footnotetext{
${ }^{1}$ Recent surveys on the relationship between trade and income distribution in developed countries can be found from
} 
disappears, so that inequality declines. As the leading group goes to an even higher level of specialization, leaving others behind, dual structure emerges and inequality increases again. As latecomers catch up, the dual structure disappears and inequality decreases again. This ratcheting process of inequality and equality generates fluctuation of the degree of inequality of income distribution. This implies that the relationship between inequality and economic development is neither monotonically positive nor monotonically negative. It may not be a simple inverted Ucurve.

The intuition behind the model is as follows. If the relationship between inequality and economic development is monotonic, then in the very developed country, income distribution must be either extremely equal or extremely unequal. This is true too for an inverted U-curve between inequality and per capital income. But we cannot see either of these two extreme cases. Hence, inequality of income distribution must fluctuate as the equilibrium level of division of labor evolves. This evolution gets a group of individuals involved in a higher level of division of labor earlier than others. Hence, a dual structure in which some individuals are more specialized (or more commercialized) than others keeps emerging and disappearing as the equilibrium level of division of labor increases. A new data set in Deininger and Squire (1996) supports our hypothesis. It indicates that there is no systematical link between growth and changes in aggregate inequality.

The second purpose of the current paper is to explore the intrinsic relationship between the development of division of labor and changes in inequality of income distribution. Kuznetz (1955) explained inequality of income distribution by per capita income. This is certainly not a general equilibrium view since per capita income is endogenous in a general equilibrium model,

Cline (1997), Williamson (1998), and Burtless (1995). 
which itself should be explained by parameters. Murphy, Shleifer, and Vishny (1989) show that unequal income distribution restricts the extent of the market, so that economies of scale cannot be fully exploited and economic development is retarded. We put this idea together with Allyn Young's conjecture that "not only division of labor is dependent on the extent of the market, but also, the extent of the market is determined by the level of division of labor", to develop a general equilibrium mechanism that simultaneously determines the extent of the market, the level of division of labor, productivity, and degree of inequality of income distribution.

We will examine effects of the coexistence of exogenous and endogneous comparative advantages on inequality of income distribution. Yang (1994) and Yang and Borland (1991) have drawn the distinction between David Ricardo's exogenous comparative advantage (Ricardo, 1817) and Adam Smith's endogenous comparative advantage (Smith, 1776). ${ }^{2}$ There is an extensive literature on exogenous comparative advantage in trade theory (see, for instance, Dixit and Norman, 1980). Separately, there are many models of endogenous comparative advantage in the growing literature on endogenous specialization (see Yang and $\mathrm{Ng}, 1998$ for a recent survey on this literature and references there). The current paper develops a general equilibrium model with the trade off between transaction costs and endogenous and exogenous comparative advantages. We shall show that as transaction conditions are improved, the scope for efficiently balancing this trade off is enlarged. Hence, the equilibrium level of division of labor increases. The existence of exogenous comparative advantage implies that different types of individuals are sequentially involved in the division of labor. Part of the population are first involved in a low level of division of labor, the rest being left behind. The emergence of this dual structure

\footnotetext{
${ }^{2}$ Endogenous comparative advantage is associated with economies of specialization and referred to by Grossman and Helpman (1991) as acquired comparative advantage, whereas exogenous comparative advantage is associated with constant returns to scale in production, referred to by them as natural comparative advantage.
} 
increases inequality of income distribution. Then the rest of the population are involved in this low level of division of labor, catching up rich fellows. This catch up process reduces duality and related inequality. Then, part of the population go to an even higher level of division of labor, increasing duality and related inequality. Then the rest who are left behind catch up, reducing duality and inequality again. This ratcheting process goes on, generating fluctuation of the degree of duality of economic structure and of the degree of inequality of income distribution. In this development process, the most important determinant of equilibrium aggregate productivity and welfare is transaction condition rather than inequality of income distribution. This is called irrelevance of inequality (or equality) of income distribution to economic development.

Early studies of structural changes and dual structure rely on the assumption of disequilibrium in some markets to predict dual structure and structural changes. For instance, Lewis (1955) tried to explain dual structure between commercialized and self-sufficient sectors by evolution of division of labor and related productivity progress (see also Ranis, 1988). Due to lack of appropriate analytical tools, he ended up with a model based on disequilibrium in labor market caused by institutional wage. Chenery (1979) used market disequilibrium to explain structural changes. Recently, general equilibrium models are used to study dual structure. In some of these models, such as in Khandker and Rashid's equilibrium model (1995), dual structure is exogenously assumed. ${ }^{3}$ They cannot predict the emergence and evolution of dual structure. In a recent literature of formal equilibrium models of high development economics, evolution of dual structure between the manufacturing sector with economies of scale in production and the agricultural sector with constant returns to scale can be predicted (see Krugman and Vanables, 1995, 1996, and Fujita and Krugman, 1995). The equilibrium models 
with endogenous geographical location of economic activities of Krugman and Venables (1995)

and Baldwin and Venables (1995) attribute the emergence of dual structure to the geographical concentration of economic activities in economic development that marginalizes peripheral areas. Kelly (1997), based on Murphy, Shleifer, and Vishny (1989), develops a dynamic general equilibrium model that predicts spontaneous evolution of a dual structure between the modern sector with economies of scale and the traditional sector with constant returns technology. As transaction conditions are sufficiently improved, the level of division of labor increases and dual structure disappears. Our model in this paper is complementary to these general equilibrium models that predict the emergence and evolution of dual structure. We pay more attention to the effects of evolution of individuals' levels of specialization and the coexistence of exogenous and endogenous comparative advantages on the emergence and evolution of dual structure. ${ }^{4}$

The rest of this paper is organized as follows. Section 2 presents the $2 \times 2$ Ricardian model with transaction costs and endogenous and exogenous comparative advantages. Section 3 solves for general equilibrium and its inframarginal comparative statics. Section 4 extends the analysis to consider not only income distribution in the developing country but also that in the developed country. The concluding section summarizes the findings of the paper and suggests possible extensions.

\section{A Ricardian Model with Endogenous and Exogenous Comparative Advantages}

Consider a world consisting of country 1 and country 2 , each with $M_{i}(i=1,2)$ consumerproducers. The set of individuals is a continuum and mass of population is 1 . There are two types of individuals in country 1 . The mass of type a persons is $M_{\mathrm{a}}$ and that of type bersons is

\footnotetext{
${ }^{3}$ Also, in Dixit's dynamic planning model (1968), the existence of labor surplus is exogenously assumed.

${ }^{4}$ Mokyr (1993, pp. 65-66) documents evolution of individuals' level of specialization during the Industrial Revolution in Britain. This evolution is sometimes referred to as "industrious revolution" which implies that selfprovided home production is replaced with commercialized production. Yang, Wang, and Wills (1992) find empirical evidence for this evolution from China's data. A difference in empirical implications generated by the Krugman and Venables model and our model is that the former yields scale effects (productivity of the manufacturing firm increases if and only if its size increases), but the latter does not.
} 
$M_{\mathrm{b}}$, where $M_{\mathrm{a}}+M_{\mathrm{a}}+M_{2}=1$. All individuals in country 2 are assumed to be identical, but different from individuals in country 1 . The utility function for individuals of type $i$ is

$$
U_{i}=\left(x_{i}+k_{i} x_{i}^{d}\right)^{\beta}\left(y_{i}+k_{i} y_{i}^{d}\right)^{1-\beta}, \quad \mathrm{i}=\mathrm{a}, \mathrm{b}, 2 .
$$

where $x_{i}, y_{i}$ are quantities of goods $\mathrm{x}$ and y produced for self-consumption, $x_{i}{ }^{d}, y_{i}{ }^{d}$ are quantities of the two goods bought from the market, and $k_{i}$ is the transaction efficiency coefficient for a type $\mathrm{i}$ individual. The transaction cost is assumed to take the iceberg form: for each unit of good bought, a fraction $1-k_{i}$ is lost in transit, the remaining fraction $k_{i}$ is received by the buyer. Type a persons and type $\mathrm{b}$ persons are distinguished by their transaction conditions. We assume that $k_{\mathrm{a}}=$ $k, k_{\mathrm{b}}=t$, and $k>t$. In other words, each type a persons has higher transaction efficiency than each type $\mathrm{b}$ person. Also, we assume that $k_{2}=k$. The assumptions can be interpreted as follows. Country 1 is a developed country which has better transaction conditions. Country 2 is a less developed country where some residents (who might be urban or coastal residents) have the same transaction condition as in developed country, but the rest of the population have lower transaction efficiency.

The production conditions are the same for all individuals in the same country, but different between the countries. Hence, the production functions for a type i consumer-producer are

$$
\begin{array}{ll}
x_{\mathrm{j}}+x_{\mathrm{j}}{ }^{\mathrm{s}}=L_{\mathrm{jx}}{ }^{c}, & y_{\mathrm{j}}+y_{\mathrm{j}}^{\mathrm{s}}=L_{\mathrm{jy}}, \quad \mathrm{j}=\mathrm{a}, \mathrm{b} . \\
x_{2}+x_{2}{ }^{\mathrm{s}}=L_{2 \mathrm{x}}{ }^{c}, & y_{2}+y_{2}{ }^{\mathrm{s}}=r L_{2 \mathrm{y}},
\end{array}
$$

where $x_{\mathrm{i}}^{\mathrm{s}}, y_{\mathrm{i}}^{\mathrm{s}}$ are respective quantities of the two goods sold by a type i person; $L_{\mathrm{is}}$ is the amount of labor allocated to the production of $\operatorname{good} \mathrm{s}(=\mathrm{x}, \mathrm{y})$ by a type i person, and $L_{\mathrm{ix}}+L_{\mathrm{iy}}=B>1$. For simplicity, we assume that $B=2$. It is assumed that $r, c>1$. This system of production functions and endowment constraint displays economies of specialization in producing good $\mathrm{x}$ and constant returns to specialization in producing good y. But an individual in country 2 has a higher productivity in producing good $y$ than an individual in country 1. Economies of specialization are individual specific and activity specific, that is they are localized increasing returns, which are compatible with the Walrasian regime.

If all individuals allocate the same amount of labor to the production of each goods, then an individual in country 1 has the same average labor productivity of good $\mathrm{x}$ as an individual in country 2. But the average and marginal labor productivity of good y for an individual in country 
2 is higher. This is similar to the situation in a Ricardian model with exogenous comparative advantage. Country 1's productivities are not higher than country 2 in producing all goods, but may have exogenous comparative advantage in producing good $\mathrm{x}$. But if an individual in country 2 allocates much more labor to the production of $\mathrm{x}$ than an individual in country 1, her productivity is higher than that of the latter. Similarly, if an individual in country 1 allocates more labor to the production of good $\mathrm{x}$ than an individual in country 2 , her productivity of good $\mathrm{x}$ will be higher. This is referred to as endogenous comparative advantage, since individuals' decisions on labor allocation determine difference in productivity between them. But an individual in country 1 has no endogenous comparative advantage in producing good y since her marginal and average productivity of $\mathrm{y}$ is always 1 , lower than $r$, independent of her labor allocation. However, country 1 has exogenous comparative advantage in producing $\mathrm{x}$ and country 2 has exogenous comparative advantage in producing y.

The decision problem for a type i individual involves deciding on what and how much to produce for self-consumption, to sell and to buy from the market. In other words, the individual chooses six variables $x_{i}, x_{i}{ }^{s}, x_{i}{ }^{d}, y_{i}, y_{i}{ }^{s}, y_{i}{ }^{d} \geq 0$. Hence, there are $2^{6}=64$ possible corner and interior solutions. As shown by Wen (1998), for such a model, an individual never simultaneously sells and buys the same good, never simultaneously produces and buys the same good, and never sells more than one good. We refer to each individual's choice of what to produce, buy and sell that is consistent with the Wen theorem as a configuration.

There are three configurations from which the individuals can choose:

(1) self sufficiency. Configuration A, where an individual produces both goods for selfconsumption. This configuration is defined by

$x_{i}, y_{i}>0, x_{i}^{s}=x_{i}^{d}=y_{i}^{s}=y_{i}^{d}=0, \mathrm{i}=\mathrm{a}, \mathrm{b}, 2$.

(2) specialization in producing good $x$. Configuration $(\mathrm{x} / \mathrm{y})$, where an individual produces only $\mathrm{x}$, sells $\mathrm{x}$ in exchange for $\mathrm{y}$, is defined by $x_{i}, x_{i}^{s}, y_{i}{ }^{d}>0, x_{i}{ }^{d}=y_{i}=y_{i}{ }^{s}=0$.

(3) specialization in producing good $y$. Configuration $(\mathrm{y} / \mathrm{x})$, where an individual produces only $\mathrm{y}$, sells $\mathrm{y}$ in exchange for $\mathrm{x}$, is defined by $y_{i}, y_{i}{ }^{s}, x_{i}{ }^{d}>0, y_{i}{ }^{d}=x_{i}=x_{i}{ }^{s}=0$. 
The combination of all individual's configurations constitutes a market structure, or structure for short. Given the configurations listed above, five structures may occur in equilibrium.

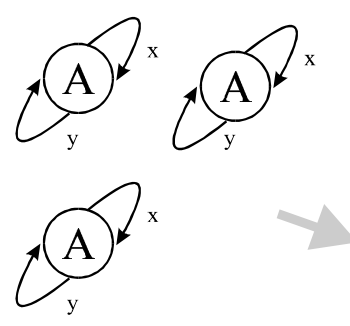

country 1 country 2 (1) Structure AAA
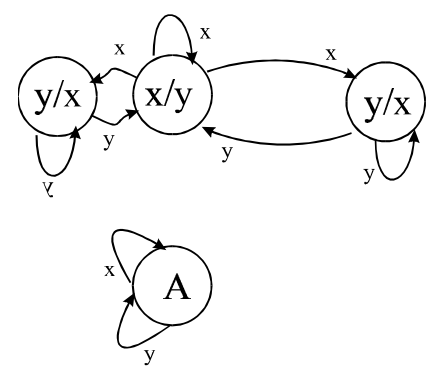

country 1 country 2

(4) Structure DAY

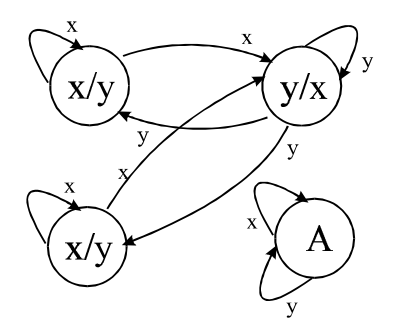

country $1 \quad$ country 2

(7) Structure XXP

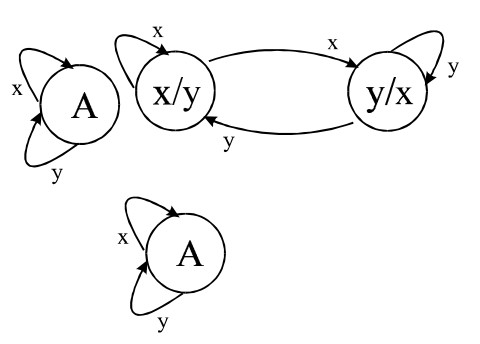

country 1 country 2

(2) Structure PAY
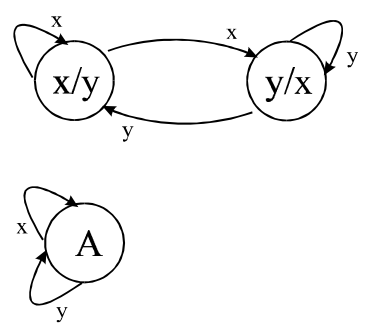

country 1 country 2

(5) Structure XAY

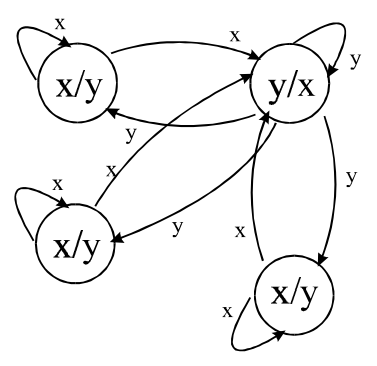

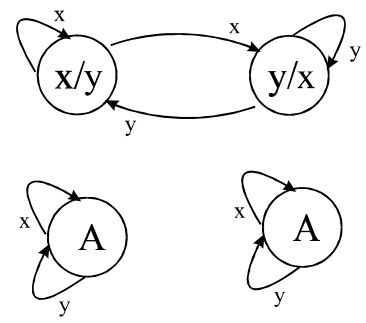

country 1 country 2

(3) Structure XAP

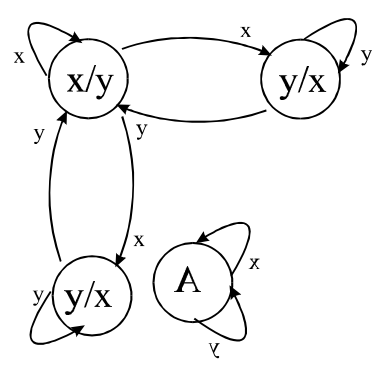

country 1 country 2

(6) Structure XPY

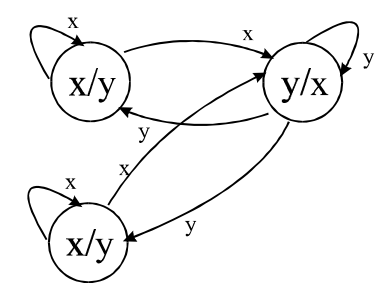

country 1 country 2

(9) Structure XXY

\section{Figure 1: Configurations and Structures}

Structure AAA, as shown in panel (1) of Fig. 1, is an autarky structure where individuals in both countries choose self-sufficiency (configuration A). Here, the first two letters denote the configurations chosen by type a and type b persons, respectively in country 1 and the third letter 
denotes the configuration chosen by individuals in country 2. In each panel up-left circles represent configurations chosen by type a individuals, down-left circles represent configurations chosen by type $b$ individuals, and circles on the right hand side represent configurations chosen by individuals in country 2 ,

Structure PAY, shown in panel (2) of Fig. 1, means that some type a persons choose configuration $(\mathrm{x} / \mathrm{y})$ and others choose autarky, all type $\mathrm{b}$ persons choose autarky, and individuals in country 2 choose configuration $(\mathrm{y} / \mathrm{x})$. Letter $\mathrm{P}$ stands for a type persons partially involved in the division of labor: some of them completely specialize and others choose autarky. This structure involves three types of dual structure. In a type I dual structure ex ante identical individuals are divided between specialization and autarky. In a type II dual structure, different types of individuals in the same country are divided between specialization and autarky. In a type III dual structure, one country is completely involved in the division of labor, while some residents in the other country are self-sufficient.

Structure XAP, shown in panel (3) of Fig. 1, means that all type a persons choose configuration (x/y), all type b persons choose autarky, some individuals in country 2 choose (y/x) and others choose autarky.

Structure DAY, shown in panel (4) of Fig. 1, means that some type a persons choose (x/y) and others choose $(\mathrm{y} / \mathrm{x})$, all type $\mathrm{b}$ persons choose autarky, and individuals in country 2 choose $(y / x)$. Letter D stands for division of individuals of a certain type between $(x / y)$ and $(y / x)$.

Structure XAY, shown in panel (5) of Fig. 1, means that all type a persons choose (x/y), all type $\mathrm{b}$ persons choose autarky, and individuals in country 2 choose configuration $(\mathrm{y} / \mathrm{x})$.

Structure XAD implies that all type a persons choose (x/y), all type b persons choose autarky, some individuals in country 2 choose $(y / x)$ and others choose $(x / y)$.

Structure XPY, shown in panel (6), means that all type a persons choose (x/y), some type $\mathrm{b}$ persons choose autarky and others choose $(\mathrm{x} / \mathrm{y})$, and individuals in country 2 choose configuration $(\mathrm{y} / \mathrm{x})$.

Structure XXP, shown in panel (7), means that all type a and type $b$ persons choose (x/y), some individuals in country 2 choose configuration (y/x), and others choose autarky.

Structure XXD, shown in panel (8), means that all type a and type b persons choose (x/y), some individuals in country 2 choose configuration $(\mathrm{y} / \mathrm{x})$, and others choose $(\mathrm{x} / \mathrm{y})$. 
Structure XXY, shown in panel (9), implies all type a and type b persons choose (x/y) and all individuals in country 2 choose configuration $(\mathrm{y} / \mathrm{x})$.

Structure XDY means that all type a persons choose $(\mathrm{x} / \mathrm{y})$, some and type $\mathrm{b}$ individuals choose $(\mathrm{x} / \mathrm{y})$ and others choose $(\mathrm{y} / \mathrm{x})$, all individuals in country 2 choose configuration $(\mathrm{y} / \mathrm{x})$.

Structure YDY means that all type a persons choose $(\mathrm{y} / \mathrm{x})$, some type $\mathrm{b}$ individuals choose $(\mathrm{x} / \mathrm{y})$ and others choose $(\mathrm{y} / \mathrm{x})$, all individuals in country 2 choose configuration $(\mathrm{y} / \mathrm{x})$.

Structure DXY means that some type a persons and all type $b$ persons choose $(\mathrm{x} / \mathrm{y})$, other type a persons choose $(y / x)$, all individuals in country 2 choose configuration $(y / x)$.

Structure DYY means that some type a persons and all type $b$ persons choose $(\mathrm{y} / \mathrm{x})$, other type a persons choose $(\mathrm{x} / \mathrm{x})$, all individuals in country 2 choose configuration.

It can be shown that other structures cannot occur in equilibrium.

\section{General Equilibrium and Its Inframarginal Comparative Statics}

According to Zhou, Sun, and Yang (1998), a general equilibrium exists and is Pareto optimal for the kind of the models in this paper under the assumptions that the set of individuals is a continuum, preferences are strictly increasing and rational; both local increasing returns and constant returns are allowed in production and transactions. Also, the set of equilibrium allocations is equivalent to the set of core allocations. An equilibrium in this model is defined as a relative price of the two goods and all individuals' labor allocations and trade plans, such that

(a) Each individual maximizes her utility, that is, the consumption bundle generated by her labor allocation and trade plan maximizes utility function (1) for given $p$.

(b) All markets clear.

For simplicity, we assume that $\beta=0.5$. Let the number (measure) of type i individuals choosing configuration (x/y) be $M_{\mathrm{ix}}$, that choosing (y/x) be $M_{\mathrm{i}}$, and that choosing A be $M_{\mathrm{iA}}$.

Since the interior solution is never optimal in this model of endogenous specialization and there are many structures based on corner solutions, we cannot use standard marginal analysis to solve for a general equilibrium. We adopt a two step approach to solving for a general equilibrium. In the first step, we consider a structure. Each individual's utility maximizing decision is solved for the given structure. Utility equalization condition between individuals choosing different configurations in the same country and market clearing condition are used to 
solve the relative price of traded goods and numbers (measure) of individuals choosing different configurations. The relative price and numbers, and associated resource allocation are referred to as a corner equilibrium for this structure.

According to the definition, a general equilibrium is a corner equilibrium in which all individuals have no incentive to deviate, under the corner equilibrium relative price, from their chosen configurations. Hence, in the second step, we can plug the corner equilibrium relative price into the indirect utility function for each configuration, then compare corner equilibrium values of utility across all configurations. The comparisons are called total cost-benefit analysis which yields the conditions under which the corner equilibrium utility in each constituent configuration of this structure is not smaller than any alternative configuration. This system of inequalities can thus be used to identify a subspace of parameter space within which this corner equilibrium is a general equilibrium.

With the existence theorem of general equilibrium proved by Zhou, Sun, and Yang (1998), we can completely partition the parameter space into subspaces, within each of which the corner equilibrium in a structure is a general equilibrium. As parameter values shift between the subspaces, the general equilibrium will discontinuously jump between structures. The discontinuous jumps of structure and all endogenous variables are called inframarginal comparative statics of general equilibrium.

We now take the first step of the inframarginal analysis. As an example, we consider structure XAP. Assume that in this structure, $M_{2 \mathrm{y}}$ individuals choose configuration $(\mathrm{y} / \mathrm{x})$ and $M_{2 \mathrm{~A}}$ individuals choose autarky in country 2 , where $M_{2 \mathrm{y}}+M_{2 \mathrm{~A}}=M_{2} . M_{\mathrm{a}}$ individuals choose configuration (x/y) and $M_{\mathrm{b}}$ individuals choose configuration A in country 1 . Since all individuals in country 2 are ex ante identical in all aspects, the maximum utilities in configurations $\mathrm{A}$ and $(y / x)$ must be the same in country 2 in equilibrium. Marginal analysis of the decision problem for an individual in country 2 choosing autarky yields her maximum utility in configuration $\mathrm{A}: U_{2 \mathrm{~A}}=$ $\left(r 2^{c+1} \gamma\right)^{0.5}$, where $\gamma \equiv c^{c} /(c+1)^{c+1}$. Marginal analysis of the decision problem for an individual in country 2 choosing configuration $(\mathrm{y} / \mathrm{x})$ yields the demand function $x_{2}{ }^{\mathrm{d}}=r / p$, the supply function $y_{2}{ }^{\mathrm{s}}=r$, and indirect utility function: $U_{2 \mathrm{y}}=r(k / p)^{0.5}$. The utility equalization condition $U_{2 \mathrm{y}}=U_{2 \mathrm{~A}}$ yields $p \equiv p_{\mathrm{x}} / p_{\mathrm{y}}=k r / 2^{c+1} \gamma$. Similarly, the marginal analysis of the decision problem of a type a individual choosing configuration $(\mathrm{x} / \mathrm{y})$ yields the demand function, $y_{1}{ }^{\mathrm{d}}=2^{c-1} / p$, the supply 
function $x_{1}^{\mathrm{s}}=2^{c-1}$, and indirect utility function: $U_{1 \mathrm{x}}=2^{\mathrm{c}-1}(\mathrm{kp})^{0.5}$. The marginal analysis of the decision problem for a type $\mathrm{b}$ individual choosing configuration $\mathrm{A}$ in country 1 yields her maximum utility in autarky $U_{\mathrm{bA}}=\left(2^{c+1} \gamma\right)^{0.5}$. Inserting the corner equilibrium relative price into the market clearing condition for good $\mathrm{x}, M_{\mathrm{ax}} x_{\mathrm{a}}^{\mathrm{s}}=M_{2 \mathrm{y}} x_{2}^{\mathrm{d}}$, yields the number of individuals selling good $\mathrm{y}, M_{2 \mathrm{y}}=k M_{\mathrm{a}} / 4 \gamma, M_{\mathrm{ax}}=M_{\mathrm{a}}$, and $M_{\mathrm{bx}}=M_{\mathrm{b}}$. Indirect utility functions for individuals choosing various configurations in the two countries are listed in Table 1.

\section{Table 1: Indirect Utility Functions}

\begin{tabular}{|l|l|l|l|}
\hline & \multicolumn{4}{l|}{ Indirect utility functions } \\
\hline Configurations & $(\mathrm{x} / \mathrm{y})$ & $(\mathrm{y} / \mathrm{x})$ & $\mathrm{A}$ \\
\hline Type a person & $U_{\mathrm{ax}}=2^{\mathrm{c}-1}(k p)^{0.5}$ & $U_{\mathrm{ay}}=(k / p)^{0.5}$ & $U_{\mathrm{aA}}=\left(2^{\mathrm{c}+1} \gamma\right)^{0.5}$ \\
\hline Type b person & $U_{\mathrm{bx}}=2^{\mathrm{c}-1}(t p)^{0.5}$ & $U_{\mathrm{by}}=(t / p)^{0.5}$ & $U_{\mathrm{bA}}=\left(2^{\mathrm{c}+1} \gamma\right)^{0.5}$ \\
\hline Country 2 & $U_{2 \mathrm{x}}=2^{\mathrm{c}-1}(k p)^{0.5}$ & $U_{2 \mathrm{y}}=r(k / p)^{0.5}$ & $U_{2 \mathrm{~A}}=\left(2^{\mathrm{c}+1} r \gamma\right)^{0.5}$ \\
\hline
\end{tabular}

Following this procedure, we can solve for corner equilibrium in each structure. The solutions of all corner equilibria are summarized in Table 2. Then we can take the second step to carry out total cost-benefit analysis for each corner equilibrium and to identify the parameter subspace within which the corner equilibrium is a general equilibrium. Consider the corner equilibrium in structure XAP as an example again. 
Table 2: Corner Equilibria

\begin{tabular}{|c|c|c|}
\hline Structure & $\begin{array}{l}\text { Relative price of } \\
\mathrm{x} \text { to } \mathrm{y}\end{array}$ & $\begin{array}{l}\text { Numbers of individuals choosing various } \\
\text { configurations }\end{array}$ \\
\hline AAA & & $M_{\mathrm{aA}}=M_{\mathrm{a}}, M_{\mathrm{bA}}=M_{\mathrm{b}}, M_{2 \mathrm{~A}}=M_{2}$ \\
\hline PAY & $\gamma 2^{3-\mathrm{c}} / k$ & $M_{\mathrm{ax}}=M_{2} k r / 4 \gamma \cdot M_{\mathrm{aA}}=M_{\mathrm{a}}-M_{2} k r / 4 \gamma, M_{\mathrm{bA}}=M_{\mathrm{b}}, M_{2 \mathrm{~A}}=M_{2}$ \\
\hline XAP & $k r / \gamma 2^{\mathrm{c}+1}$ & $\begin{array}{l}M_{\mathrm{ax}}=M_{\mathrm{a}}, M_{\mathrm{bA}}=M_{\mathrm{b}} \\
M_{2 \mathrm{y}}=M_{\mathrm{a}} k / 4 \gamma, M_{2 \mathrm{~A}}=M_{2^{-}}\left(M_{\mathrm{a}} k / 4 \gamma\right)\end{array}$ \\
\hline DAY & $2^{1-c}$ & $M_{\mathrm{ax}}=\left(M_{\mathrm{a}}+r M_{2}\right) / 2, M_{\mathrm{ay}}=\left(M_{\mathrm{a}}-r M_{2}\right) / 2, M_{\mathrm{bA}}=M_{\mathrm{b}}, M_{2 \mathrm{y}}=M_{2}$ \\
\hline XAY & $M_{2} r 2^{1-\mathrm{c}} / M_{\mathrm{a}}$ & $M_{\mathrm{aA}}=M_{\mathrm{a}}, M_{\mathrm{bA}}=M_{\mathrm{b}}, M_{2 \mathrm{y}}=M_{2}$ \\
\hline $\mathrm{XAD}$ & $r 2^{1-c}$ & $M_{\mathrm{ax}}=M_{\mathrm{a}}, M_{\mathrm{bA}}=M_{\mathrm{b}}, M_{2 \mathrm{y}}=\left(M_{\mathrm{a}}+M_{2}\right) / 2$ \\
\hline XPY & $\gamma 2^{3-\mathrm{c}} / k$ & $M_{\mathrm{ax}}=M_{\mathrm{a}}, M_{\mathrm{bx}}=\left(k r M_{2} / 4 \gamma\right)-M_{\mathrm{a}}, M_{2 \mathrm{y}}=M_{2}$ \\
\hline XXP & $k r / \gamma 2^{c+1}$ & $\begin{array}{l}M_{\mathrm{ax}}=M_{\mathrm{a}}, M_{\mathrm{bx}}=M_{\mathrm{b}}, \\
M_{2 \mathrm{y}}=k\left(M_{\mathrm{a}}+M_{\mathrm{b}}\right) / 4 \gamma, M_{2 \mathrm{~A}}=M_{2^{-}}\left[k\left(M_{\mathrm{a}}+M_{\mathrm{b}}\right) / 4 \gamma\right]\end{array}$ \\
\hline XXD & $r 2^{1-c}$ & $\begin{array}{l}M_{\mathrm{ax}}=M_{\mathrm{a}}, M_{\mathrm{bx}}=M_{\mathrm{b}} \\
M_{2 \mathrm{y}}=\left(M_{\mathrm{a}}+M_{\mathrm{b}}+M_{2}\right) / 2, M_{2 \mathrm{x}}=\left(M_{2}-M_{\mathrm{a}}-M_{\mathrm{b}}\right) / 2\end{array}$ \\
\hline $\mathrm{XXY}$ & $M_{2} r 2^{1-\mathrm{c}} /\left(M_{\mathrm{a}}+M_{\mathrm{b}}\right)$ & $M_{\mathrm{ax}}=M_{\mathrm{a}}, M_{\mathrm{bx}}=M_{\mathrm{b}}, M_{2 \mathrm{y}}=M_{2}$ \\
\hline $\mathrm{XDY}$ & $2^{1-c}$ & $\begin{array}{l}M_{\mathrm{ax}}=M_{\mathrm{a}}, \quad M_{\mathrm{bx}}=\left(M_{\mathrm{b}}-M_{\mathrm{a}}+r M_{2}\right) / 2, \quad M_{\mathrm{by}}=\left(M_{\mathrm{a}}+M_{\mathrm{b}}-r M_{2}\right) / 2, \\
M_{2 \mathrm{y}}=M_{2}\end{array}$ \\
\hline YDY & $2^{1-c}$ & $\begin{array}{l}M_{\mathrm{ay}}=M_{\mathrm{a}}, \quad M_{\mathrm{bx}}=\left(M_{\mathrm{a}}+M_{\mathrm{b}}+r M_{2}\right) / 2, \quad M_{\mathrm{by}}=\left(M_{\mathrm{b}}-M_{\mathrm{a}}-r M_{2}\right) / 2, \\
M_{2 \mathrm{y}}=M_{2}\end{array}$ \\
\hline DXY & $2^{1-c}$ & $\begin{array}{l}M_{\mathrm{bx}}=M_{\mathrm{b}}, \quad M_{\mathrm{ax}}=\left(M_{\mathrm{a}}-M_{\mathrm{b}}+r M_{2}\right) / 2, \quad M_{\mathrm{ay}}=\left(M_{\mathrm{a}}+M_{\mathrm{b}}-r M_{2}\right) / 2, \\
M_{2 \mathrm{y}}=M_{2}\end{array}$ \\
\hline DYY & $2^{1-c}$ & $\begin{array}{l}M_{\mathrm{bx}}=M_{\mathrm{b}}, \quad M_{\mathrm{bx}}=\left(M_{\mathrm{a}}+M_{\mathrm{b}}+r M_{2}\right) / 2, \quad M_{\mathrm{ay}}=\left(M_{\mathrm{a}}-M_{\mathrm{b}}-r M_{2}\right) / 2, \\
M_{2 \mathrm{y}}=M_{2}\end{array}$ \\
\hline
\end{tabular}

In this structure $M_{\mathrm{a}}$ individuals choose configuration (x/y) and $M_{\mathrm{bA}}$ individuals choose autarky in country 1 , and $M_{2 \mathrm{y}}$ individuals choose configuration $(\mathrm{y} / \mathrm{x})$ and $M_{2 \mathrm{~A}}$ individuals choose autarky in country 2 . For a type a person in country 1 , equilibrium requires that her utility in configuration $(\mathrm{x} / \mathrm{y})$ is not smaller than in configurations $(\mathrm{y} / \mathrm{x})$ and $\mathrm{A}$ under the corner equilibrium relative price in structure XAY. Also equilibrium requires that all type $b$ persons in country 1 prefer autarky to configurations $(\mathrm{x} / \mathrm{y})$ and $(\mathrm{y} / \mathrm{x})$ and that all individuals in country 2 are indifferent between configurations $(\mathrm{y} / \mathrm{x})$ and $\mathrm{A}$ and receive a utility level that is not lower than in configuration (x/y). In addition, this structure occurs in equilibrium only if $M_{2 y} \in\left(0, M_{2}\right)$. All the conditions imply

$$
\begin{aligned}
& U_{\mathrm{ax}} \geq U_{\mathrm{ay}}, \quad U_{\mathrm{ax}} \geq U_{\mathrm{aA}}, \quad U_{\mathrm{bA}} \geq U_{\mathrm{bx}}, \quad U_{\mathrm{bA}} \geq U_{\mathrm{by}}, \\
& U_{2 \mathrm{~A}}=U_{2 \mathrm{y}} \geq U_{2 \mathrm{x}}, \quad M_{2 \mathrm{y}} \in\left(0, M_{2}\right),
\end{aligned}
$$


where indirect utility functions in different configurations and corner equilibrium relative price are given in Tables 1 and 2. The conditions define a parameter subspace:

$$
k t<16 \gamma^{2} / r, \quad k \in\left(4 \gamma / \sqrt{ } r, \operatorname{Min}\left\{4 \gamma, 4 M_{2} \gamma / M_{\mathrm{a}}\right\}\right),
$$

where $\gamma \equiv c^{c} /(c+1)^{c+1}$. Within this parameter subspace, the corner equilibrium in structure XAP is the general equilibrium. Following this procedure, we can do total cost-benefit analysis for each structure. The total cost-benefit analysis in the second step and marginal analysis of each corner equilibrium in the first step yields inframarginal comparative statics of general equilibrium, summarized in Table 3. From this Table, we can see that the parameter subspaces for structure AAD, XAA, and all structures in which country 1 exports y and country 2 exports $\mathrm{x}$ to occur in general equilibrium are empty.

Table 3: General Equilibrium Structure: Inframarginal Comparative Statics

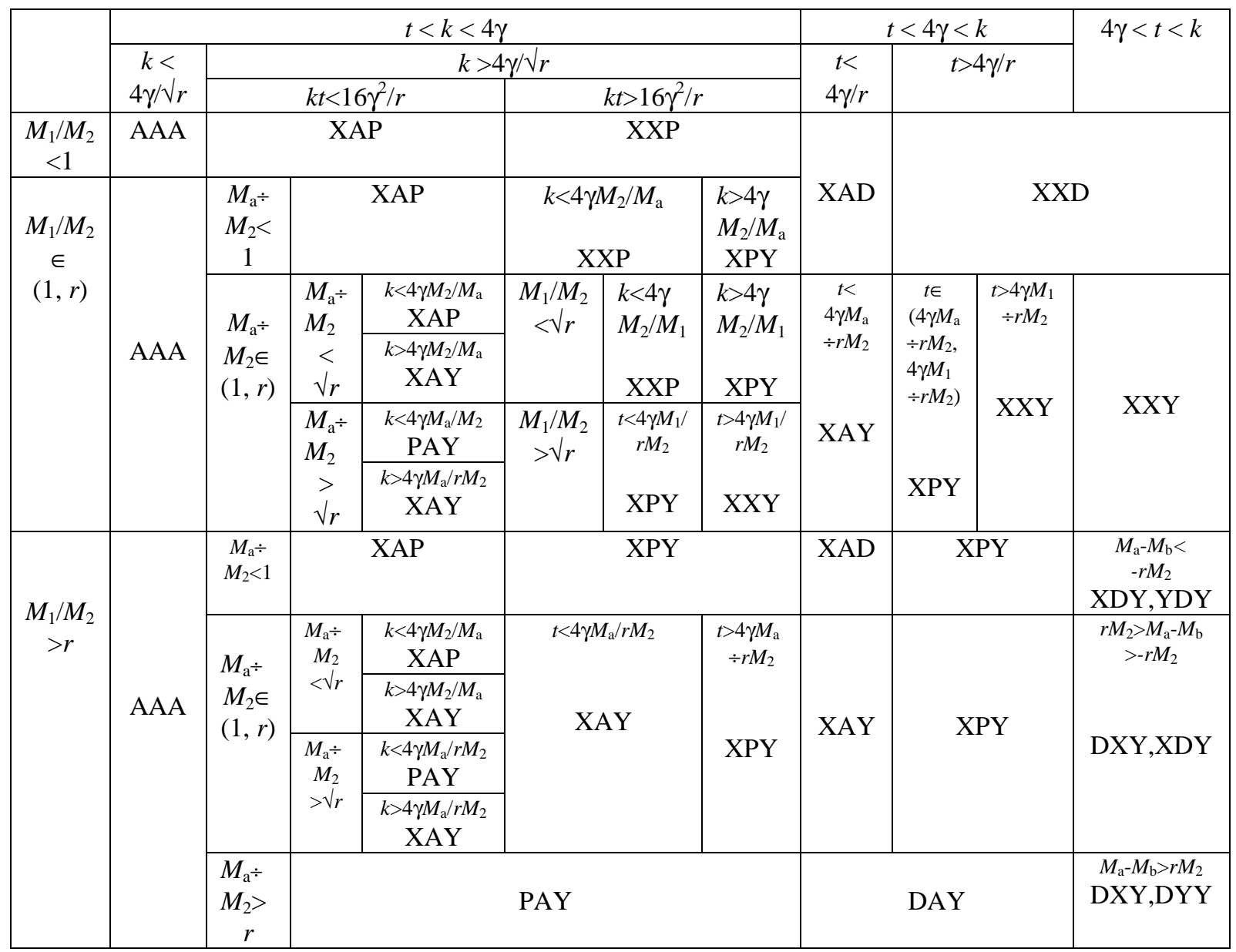


where $\gamma \equiv c^{c} /(1+c)^{c+1}$. X stands for configuration $(\mathrm{x} / \mathrm{y})$ chosen by individuals of a certain type, $\mathrm{Y}$ stands for $(\mathrm{y} / \mathrm{x})$ chosen by individuals of a certain type, A stands for autarky, $\mathrm{P}$ stands for the partial division of labor where individuals of a certain type are divided between autarky and specialization, D stands for the division of individuals of a certain type between (x/y) and (y/x). Structure XAP involves type I and type II dual structures, Structure XXP involves type I and type III dual structures. Structures DAY, XAY, XAD involve type II and type III dual structures. Structures PAY and XPY involve all three types of dual structure.

When a dual structure occurs in equilibrium individuals in autarky look like underemployed or in underdevelopment in the sense that it receives none of gains from trade and income differential between them and other individuals who are involved in the division of labor increases as a result of a shift of equilibrium from AAA to a dual structure. These self-sufficient individuals cannot find a job to work for the market. Figure 1 illustrates the equilibrium structures. ${ }^{5}$ We say the level of division of labor increases if occurrence of letter A or P decreases and/or the occurrence of letter D, X, and/or Y increases in the equilibrium structure. We can identify five levels of division of labor. The lowest one is associated with structure AAA where all three types of individuals are self-sufficient. The second level is associated with structures PAY and XAP in each of which two types of individuals are self-sufficient. The third level is associated with structures DAY, XAY, XAD in each of which all of individuals of a certain type are self-sufficient. The fourth level is associated with structures XPY and XXP in each of which only part of the population of a certain type are self-sufficient. The fifth level is associated with structures XXD, XXY, XDY, YDY, DXY, DYY, in each of which all individuals are specialized.

With the definition of division of labor in mind, we can now have a close examination of Table 3. As transaction conditions are improved, the equilibrium level of division of labor increases. If the equilibrium level of division of labor increases from level 1 to level 2, then dual structure emerges, or duality of economic structure increases. If the equilibrium level of division of labor increases from 2 to 3 , the duality decreases as those individuals who are left behind catch up. If the equilibrium level of division of labor increases from 3 to 4, the duality increases again as some of individuals in a group that was in autarky before choose specialization. As the

\footnotetext{
${ }^{5}$ The coexistence of two equilibria distinguishes the model of endogenous specialization from a standard Arrow-
} 
equilibrium level of division of labor increases from 4 to 5 , the duality decreases again as those who were left behind catch up. But it is also possible, improvements in transaction conditions generate a jump of equilibrium from level 2 to level 4 of division of labor. Such a jump will reduce duality. A jump from level 3 of division of labor to level 5 will reduce duality too.

This analysis implies that as different groups of the same type or different types of individuals gradually choose higher level of specialization one by one, the degree of duality fluctuates. Its increase will raise inequality of income distribution and its decrease will reduce inequality. Hence, as different individuals are gradually involved in the network of division of labor as a result of improved transaction conditions, the equilibrium degree of inequality fluctuates. It does not monotonically increases or decreases. The relationship between inequality and per capita real income may not be an inverted U-curve.

Inserting the corner equilibrium relative price in Table 2 into indirect utility functions in Table 1, we can compare the difference of per capita real incomes (equilibrium levels of utility) of two types of individuals in country 1, considering the parameter subspaces that demarcate the structures. The comparisons confirm our analysis. We first consider the path of evolution in division of labor: $\mathrm{AAA} \rightarrow \mathrm{XAP} \rightarrow \mathrm{XAY} \rightarrow \mathrm{XPY} \rightarrow \mathrm{XXY}$. The difference in per capita real income between type a and type $b$ individuals in country 1 is 0 in structure AAA. It is positive in structure XAP. It decreases as the equilibrium jumps from XAP to XAY. It then increases as the equilibrium jumps from XAY to XPY. It decreases again as the equilibrium jumps from XPY to XXY.

We can find other evolutionary paths of division of labor with fluctuating degree of inequality of income distribution. Also, comparisons of ratios of the highest to the lowest real income between corner equilibria generate similar results.

All the results on evolution of division of labor, dual structure, and trade pattern are summarized in the following proposition, illustrated in Fig. 1.

Proposition 1: As transaction efficiency increases from a very low to a very high level, the equilibrium level of domestic and international division of labor increases from complete autarky in both countries to the complete division of labor in both countries. As different

Debreu equilibrium model in which the number of multiple equilibria is always odd. 
individuals are gradually involved in the division of labor, the duality of economic structure fluctuates, generating fluctuation of the equilibrium degree of inequality of income distribution in the less developed country. This degree is neither monotonically increasing nor monotonically decreasing. The relationship between the inequality and per capita real income might not be of $U$-curve.

The inframarginal comparative statics of general equilibrium in Table 3 can be used to establish two corollaries. The first is that evolution in division of labor generated by improvements in transaction conditions will raise equilibrium aggregate productivity. In order to establish the above statement, we consider the aggregate PPF for individual 1 (from country 1) and individual 2 (from country 2). As shown in Fig. 2 where $c=2$, the PPF for individual 1 is curve $\mathrm{BC}$, that for individual 2 is curve AC. In autarky, the two persons' optimum decisions for taste parameter $\beta \in(0,1)$ are functions of $\beta$. Let $\beta$ change from 0 to 1 ; we can calculate values of $Y=y_{1}+y_{2}$ and $X=x_{1}+x_{2}$ as functions of $\beta$. The values of $X$ and $Y$ for different values of $\beta$ constitute curve EGH in Fig. 2. The equilibrium aggregate production schedule in structure AAA is a point on the curve, dependent on value of $\beta$. But the aggregate PPF for the two individuals is the curve EFH. Since in a structure with complete division of labor the equilibrium production schedule is point $\mathrm{F}$ which is on the aggregate $\mathrm{PPF}$, the aggregate productivity in a structure with the complete division of labor is higher than in structure AAA. The difference between EFH and EGH can be considered as economies of division of labor.

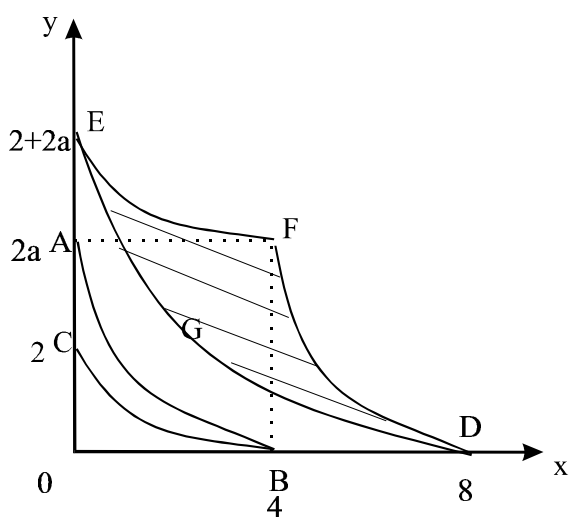

Figure 2: Economies of Division of Labor Based on Endogenous and Exogenous Comparative Advantage 
Following the same reasoning, we can prove that the equilibrium aggregate productivity in a dual structure is lower than the PPF. Hence, proposition 1 implies that as transaction efficiencies are improved, the equilibrium level of division of labor and equilibrium aggregate productivity increase side by side.

The second corollary is that deterioration of a country's terms of trade and increase of gains received by this country from trade may concur. Suppose that the initial values of parameters satisfy $\left(M_{\mathrm{a}}+M_{\mathrm{b}}\right) / M_{2} \in(\sqrt{ } r, r), M_{\mathrm{a}} / M_{2} \in(1, r), k t>16 \gamma^{2} / r$. Within this parameter subspace, Suppose that the initial value of $t$ satisfies $t^{\prime}<4 \gamma\left(M_{\mathrm{a}}+M_{\mathrm{b}}\right) / M_{2} r$. Table 3 indicates that structure XPY occurs in equilibrium where country 1 's terms of trade is $p^{\prime}=\gamma 2^{3-c} / t^{\prime}$. Now assume that $t$ increases to the value $t^{\prime \prime}$, so that $t^{\prime \prime}>4 \gamma\left(M_{\mathrm{a}}+M_{\mathrm{b}}\right) / M_{2}$. According to Table 3 , the equilibrium jumps to structure XXY where country 1 's terms of trade is $p^{\prime \prime}=M_{2} r 2^{1-\mathrm{c}} /\left(M_{\mathrm{a}}+M_{\mathrm{b}}\right)$. It can then be shown that country 1's terms of trade deteriorate as a result of the change in $t$ within the parameter subspace. But this shift of the equilibrium from XPY to XXY increases utility of each individual in country 1 if $k^{\prime} / t^{\prime}<k^{\prime \prime} M_{2} r / 4 \gamma\left(M_{\mathrm{a}}+M_{\mathrm{b}}\right)$. This has established the claim that there exists some parameter subspace within which the deterioration of a country's terms of trade may concur with an increase of gains that this country receives from trade. There are other parameter subspaces within which changes in parameters may generate concurrence of the deterioration of one country's terms of trade and an increase in its gains from trade. ${ }^{6}$

This corollary generates the following policy implications. In the transitional stage of economic development and globalization, the terms of trade are against the less developed country that has relatively low transaction efficiency: some residents in the less developed country receive autarky utility and most gains from trade go to the developed country. There are two policies to change this inferior position. One is to impose tariff to improve terms of trade and the other is to improve transaction condition to expand network of trade. The former is to increase share of gains received by the less developed country from a shrunk pie because of the deadweight caused by tariff. The latter is to get greater share of gains from trade by enlarging the pie. The expanded network of division of labor can generate productivity gains. As long as productivity improvements outpace the deterioration of terms of trade, the less developed country

\footnotetext{
${ }^{6}$ Empirical and theoretical research on economic development and terms of trade can be found, for instance from Morgan (1970), Kohli and Werner (1998), Sen (1998).
} 
can receive more gains from trade not only because of productivity gains, but also because of more equal division of gains from trade between the countries as all individuals are involved in the international and domestic division of labor.

\section{Effects of Trade on Income Distribution in the Developed Country}

Since we assume that there is only one type of individuals in the developed country which has better transaction condition, the model in the previous section cannot explore effects of economic development and international trade on income distribution in the developed country. In this section we extend the model in the previous section by specifying two types of individuals in the developed country. The new model is exactly same as previous one except that there are two types of individuals in country 2 as well. Types $1 \mathrm{a}$ and $1 \mathrm{~b}$ of individuals are in country 1 and types $2 \mathrm{a}$ and $2 \mathrm{~b}$ of individuals are in country 2 . For type $2 \mathrm{a}$ individuals, transaction efficiency is $k$, for type $1 \mathrm{~b}$ individuals, transaction efficiency is $t$, and for type $2 \mathrm{~b}$ and $1 \mathrm{a}$ individuals, transaction efficiency is $s$, where $1 \geq k>s>t \geq 0$.

For simplicity, we assume that $M_{1 \mathrm{a}}=M_{1 \mathrm{~b}}=M_{2 \mathrm{a}}=M_{2 \mathrm{~b}}=1 / 4$. Following the method in the previous section, the inframarginal comparative statics of this new model can be solved as in Table 4.

\section{Table 4: Equilibrium Structure}

\begin{tabular}{|c|c|c|c|c|c|c|c|c|c|c|}
\hline \multicolumn{4}{|c|}{$0<t<s<k<4 \gamma$} & \multicolumn{4}{|c|}{$0<t<s<4 \gamma<k<1$} & \multicolumn{2}{|c|}{$0<t<4 \gamma<s<k<1$} & \multirow{2}{*}{$\begin{array}{l}4 \gamma<t< \\
s<k<1\end{array}$} \\
\hline \multirow{2}{*}{$\begin{array}{c}k s< \\
16 \gamma^{2} / r\end{array}$} & \multicolumn{3}{|c|}{$k s>16 \gamma^{2} / r$} & \multirow[t]{2}{*}{$s<4 \gamma / r$} & \multicolumn{3}{|c|}{$s>4 \gamma / r$} & \multirow[t]{2}{*}{$t<4 \gamma / r$} & \multirow[t]{2}{*}{$t>4 \gamma / r$} & \\
\hline & $k t<16 \gamma^{2} / r$ & $k t>1$ & $\gamma^{2} / r$ & & $s t<1$ & $\gamma^{2} / r$ & $\begin{array}{c}s t>16 \gamma^{2} / \\
r\end{array}$ & & & XXYY \\
\hline \multirow{2}{*}{ AAAA } & & $t s<16 \gamma^{2} / r$ & $t s>16 \gamma^{2} /$ & \multirow{2}{*}{ AADA } & $t<4 \gamma / r$ & $t>4 \gamma / r$ & \multirow{2}{*}{ XXYP } & XAYD & \multirow{2}{*}{ XXYY } & \\
\hline & ХАРА & XPYA & XXYP & & XAYA & XPYA & & XADY & & \\
\hline
\end{tabular}

where $\gamma \equiv c^{\mathrm{c}} /(1+c)^{\mathrm{c}+1}, \mathrm{X}$ denotes configuration $(\mathrm{x} / \mathrm{y}), \mathrm{Y}$ denotes $(\mathrm{y} / \mathrm{x}), \mathrm{P}$ denotes a division of individuals of a certain type between specialization and autarky, D denotes a division of individuals of a certain type between $(\mathrm{x} / \mathrm{y})$ and $(\mathrm{y} / \mathrm{x})$. The first of four letters denoting a structure represents the configuration chosen by type 1a persons, the second represents that chosen by type 
$1 \mathrm{~b}$ persons, the third represents that chosen by type $2 \mathrm{a}$ persons, and the fourth represents that chosen by type $2 \mathrm{~b}$ persons.

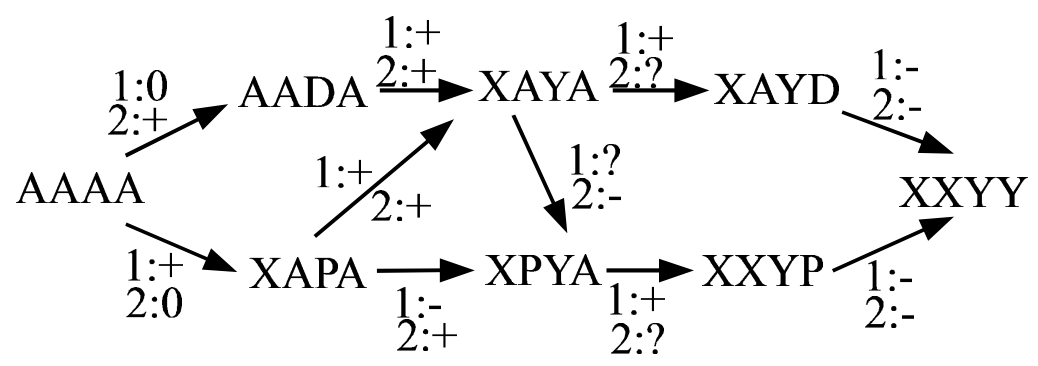

Figure 3: Evolution in Division of Labor

Figure 3 gives an intuitive illumination of the evolution of division of labor and economic development as a result of improvements in transaction conditions. In this figure, an arrow $\rightarrow$ denotes the direction of evolution of division of labor, the numbers 1 and 2 beside the arrows denote the two countries, and signs + and - denote increase and decrease, respectively, of inequality of income distribution in a country. Mark? implies that either an increase or decrease of inequality is possible. From the results, we can see that although evolutionary paths of division of labor AAAA $\rightarrow \mathrm{AADA} \rightarrow \mathrm{XAYA} \rightarrow \mathrm{XAYD} \rightarrow \mathrm{XXYY}$ generates an inverted curve of inequality in the less developed country, path $\mathrm{AAAA} \rightarrow \mathrm{XAPA} \rightarrow \mathrm{XPYA} \rightarrow \mathrm{XAYP} \rightarrow \mathrm{XXYY}$ generates fluctuation of inequality. Other paths with ? may generate such fluctuation too. Again, inframarginal comparative statics of general equilibrium confirm proposition 1 even if income distribution in the developed country is considered. This yields proposition 2.

Proposition 2: As transaction efficiency is improved, the equilibrium level of division of labor and aggregate productivity increase. The degree of inequality of income distribution in the less developed country and developed country fluctuates as duality of economic structure fluctuates. The degree of inequality is nonmonotonic and it might not be an inverted U-curve. 
An interesting feature of our inframarginal analysis of general equilibrium is that economic development and structural changes can take place in the absence of changes of tastes and production functions. All development and trade phenomena can generated by changes in transaction conditions which are neither of demand side nor of supply side. Hence, it explores the limitation of the analysis that explains trade and development phenomena by changes in demand and/or supply sides. All recent general equilibrium models of "high development economics" share this feature (see Fujita and Krugman 1995, Krugman and Venables, 1995, Kelly, 1997, Shi and Yang, 1995, Yang, 1991, and Yang and Rice, 1994, for instance).

\section{Conclusion}

In this paper, we have proposed a theory of ratcheting inequality and equality of income distribution using inframarginal analysis of a model of endogenous specialization. This theory accommodates the empirical evidence for the coexistence of positive and negative correlation between inequality and economic development which relates to trade. Because of the trade off between economies of division of labor and transaction costs, the equilibrium level of division of labor increases as transaction conditions are improved. If transaction conditions are different between countries or between different groups of individuals in the same countries, different individuals will be involved in the division of labor sequentially. If some individuals have a higher level of specialization (or commercialization) than other individuals, a dual structure will increase inequality of income distribution. As those poor individuals increase their levels of specialization, the dual structure disappears and inequality decreases. But as the level of division

of labor increases further, while some individuals' levels of specialization increases before others' do, a new dual structure will occur and then it disappears as latecomers catch up. This ratcheting process generates fluctuation of the equilibrium degree of inequality as division of labor evolves. Therefore, there is neither a monotonic relationship between inequality of income distribution and economic development nor an inverted U-curve. In other words, inequality (equality) of income distribution is irrelevant to economic development. We should pay more attention to improvements in transaction conditions that will enhance aggregate productivity and all 
individuals' welfare than to the relationship between inequality and economic development (or trade).

A logical extension of this paper is to add more goods and/or more countries and introduce tariff into the Ricardian model. More structures may occur in equilibrium and the ratcheting process will be more pronounced. If political economics of income distribution and rent seeking is considered, negative effects of unfair income distribution on economic development may be analyzed. 


\section{References}

Alesina, A. and D. Rodrik (1994), "Distributive Politics and Economic Growth," Quarterly Journal of Economics, 109, 465-90.

Baldwin, Richard E and Venables, Anthony J. (1995), "Regional Economic Integration," in Grossman, Gene M. Rogoff, Kenneth, eds., Hanbook of International Economics. Volume 3. Amsterdam; New York and Oxford: Elsevier, North-Holland.

Balassa, B. (1986) "The Employment Effects of Trade in Manufactured Products between Developed and Developing Countries." Journal of Policy Modeling, 8, 371-90.

Banerjee, A. and A. Newman (1993), "Occupational Choice and the Process of Development," Journal of Political Economy, 101, 274-98.

Barro, R. (1997), Determinants of Economic Growth, Cambridge, MA, MIT Press.

Becker, Gary (1981), A Treatise on the Family, Cambridge, Massachusetts, Harvard University Press.

Borjas, G. R. Freeman, and L. Katz (1992), "How Much Do Immigration and Trade Affect Labor Market Outcomes?" Brookings Papers on Economic Activity. No. 1, 1-67.

Buchanan, James M. and Stubblebine, W. Craig (1962), "Externality,” Economica, 29, 371-84.

Burtless, G. (1995), "International Trade and the Rise in Earnings Inequality." Journal of Economic Literature. 33, 800-16.

Chenery, M. (1979), Structural Change and Development Policy, New York, Oxford University Press.

Cline, William (1997), Trade and Income Distribution, Washington DC, Institute for International Economics.

Coase, Ronald (1946), “The Marginal Cost Controversy,” Economica, 13, 169-82.

Coase, Ronald (1960), “The Problem of Social Cost,” Journal of Law and Economics, 3, 1-44.

Cypher, James and Dietz, James (1998), "Static and Dynamic Comparative Advantage: A Multi-period Analysis with Declining Terms of Trade," Journal of Economic Issues, 32, 305-14.

Deininger, K. and L. Squire (1996), "A New Data Set Measuring Income Inequality," World Bank Economic Review, $10,565-91$.

Dixit, A. (1987), "Trade and Insurance with Moral Hazard," Journal of International Economics, 23, 201-20.

Dixit, A. (1989), "Trade and Insurance with Adverse Selection," Review of Economic Studies, 56, 235-48.

Dixit, A. and Norman, V. (1980), Theory of International Trade, Cambridge: Cambridge University Press.

Din, M. (1996), "International Capital Mobility and Development Policy in a Dual Economy," Review of International Economics, 4, 185-201.

Easton, Stephen and Michael, Walker (1997): "Income, Growth, and Economic Freedom", American Economic Review, Papers and Proceedings, 87, 328-32. 
Feenstra (1998), "Integration of Trade and Disintegration of Production in the Global Economy," Journal of Economic Perspectives, 12, 31-50.

Fei, John, Gustav Ranis, and Shirley Kuo (1979), Growth with Equity : the Taiwan Case. New York, Published for the World Bank by Oxford University Press.

Frank, C. (1977), Foreign Trade and Domestic Aid. Washington, Brookings Institute.

Frye, Timothy and Shleifer, Andrei (1997): "The Invisible Hand and the Grabbing Hand." American Economic Review, Papers and Proceedings, 87, 354-58.

Fujita, Masahisa and Krugman, Paul (1995), "When is the Economy Monocentric: von Thünen and Chamberlin Unified," Regional Science \& Urban Economics, 25, 505-28.

Gallup, John and Jeff Sachs (1998), "Geography and Economic Development," Working Paper, Harvard Institute for International Development.

Galor, O. and J. Zeira (1993), "Income Distribution and Macroeconomics," Review of Economic Studies, 87, 205-10.

Gomory, Ralph E. (1994), “A Ricardo Model with Economies of Scale,” Journal of Economic

Theory, 62, 394-419.

Greewood, J. and B. Jovanovic (1990), "Financial Development, Growth, and the Distribution of Income," Journal of Political Economy, 98, 1076-1107.

Grossman, Gene (1998), "Imperfect Labor Contracts and International Trade," memeo., Department of Economics, Princeton University..

Grossman, S. and Hart. O (1986), "The Costs and Benefits of Ownership: A Theory of Vertical and Lateral Integration," Journal of Political Economy, 94, 691-719.

Grossman, G. and Helpman, E. (1990), "Comparative Advantage and Long-Run Growth", American Economic Review, 80, 796-815.

Jones, Charles I. (1998), Introduction to Economic Growth, New York, W. W. Norton \& Company.

Karoly, L. and J. Klerman (1994), "Using Regional Data to Reexamine the Contribution of Demographic and Sectoral Changes to Increasing U.S. Wage Inequality." in The Changing Distribution of Income in an Open US Economy, ed. by J. Bergstrand et al. Amsterdam, North-Holland.

Katz, L. and K. Murphy (1992), "Changes in Relative Wages, 1963-1987: Supply and Demand Factors. Quarterly Journal of Economics. 107, 35-78.

Kelly, Morgan (1997): “The Dynamics of Smithian Growth”. Quarterly Journal of Economics, 112, 939-64.

Khandker, A. and S. Rashid (1995), "Wage Subsidy and Full Employment in a Dual Economy with Open Unemployment and Surplus Labor," Journal of Development Economics. 48, 205-23.

Kohli, Ulrich and Werner, Augustin (1998), "Accounting for South Korean GDP Growth: Index-Number and Econometric Estimates,” Pacific Economic Review, 3, 133-52.

Krugman, Paul (1996), "Does Third World Growth Hurt First World Prosperity?" Harvard Business Review, 72, $113-21$. 
Krugman, Paul (1995), “Growing World Trade: Causes and Consequences.” Brookings Paper on Economic Activity, $1,327-62$.

Krugman, Paul (1995), “Technology, Trade, and Factor Prices.” NBER Working Paper No. 5355, National Bureau of Economic Research.

Krugman,P. And A. J. Venables (1995), "Globalization and the Inequality of Nations," Quarterly Journal of Economics, 110, 857-80.

Krugman, P. and R. Lawrence (1994), “Trade, Jobs and Wages. Scientific American. 270, 44-49.

Kuznets, S. (1955), “Economic Growth and Income Inequality,'American Economic Review,'45, 1-28.

Lewis, W. (1955), The Theory of Economic Growth, London: Allen and Unwin.

Li, Hongyi and Heng-fu Zou (1998), "Income Inequality is not Harmful for Growth: Theory and Evidence." Review of Development Economics, 2, 318-34.

Mokyr, Joel, (1993), “The New Economic History and the Industrial Revolution,” in Mokyr, J. ed. The British Industrial Revolution: An Economic Perspective, Boulder and Oxford: Westview Press.

Murphy, K., Schleifer, A., and Vishny, R. (1989), "Income Distribution, Market Size, and Industrialization", The Quarterly Journal of Economics, 104, 537-64.

Murphy, K. and F. Welch (1991), "The Role of International Trade in Wage Differentials." in Workers and Their Wages: Changing Patterns in the United States. ed. by M. Kosters. Washitington, American Enterprise Institute.

Palma, Babriel (1978), "Dependency: A Formal Theory of Underdevelopment or a Methodology for the Analysis of Concrete Situations of Underdevelopment?" World Development, 6, 899-902.

Puga, Diego and Venables, Anthony (1998), "Agglomeration and Economic Development: Import Substitution vs. Trade Liberasation," Centre for Economic Performance Discussion Paper No. 377.

Ram, Rati (1997), "Level of Economic Development and Income Inequality: Evidence from the Postwar Developed World," Southern Economic Journal. 64, 576-83.

Ranis, G. (1988), “Analytics of Development: Dualism,” in Handbook of Development Economics, ed. H. Chenery and T. Srinivasan, vol. 1, 4. A good survey of dualism.

Ricardo, David (1817), The Principles of Political Economy and Taxation, London: J.M. Dent \& Sons Ltd, 1965.

Rosen, S. (1978), “Substitution and the Division of Labor,” Economica, 45, 235-50.

Rosen, S. (1983), “Specialization and Human Capital,” Journal of Labor Economics, 1, 43-49.

Sachs, Jeff (1996), "Globalization and the U.S. Labor Market." The American Economic Review: Papers and Proceedings, May.

Sachs, J. and H. Shartz (1994), "Trade and Jobs in US Manufactures. Brookings Papers on Activity. No. 1. 1-84.

Sachs, J. and Warner, A. (1995) "Economic Reform and the Process of Global Integration," Brookings Papers on Economic Activity, 1. 
Sachs, Jeffrey and Warner, Andrew (1997): "Fundamental Sources of Long-Run Growth." American Economic Review, Papers and Proceedings, 87, 184-88.

Sen, Partha (1998), "Terms of Trade and Welfare for a Developing Economy with an Imperfectly Competitive Sector," Review of Development Economics, 2, 87-93.

Smith, Adam (1776), An Inquiry into the Nature and Causes of the Wealth of Nations, reprint, Oxford: Clarendon Press, 1976.

Thompson, Henry (1995), "Free Trade and Income Redistribution in Some Developing and Newly Industrialized Countries." Open Economies Review, 6, 265-80.

Wen, M. (1998): “An Analytical Framework of Consumer-Producers, Economies of Specialisation and Transaction Costs," in K. Arrow, Y-K. Ng, X. Yang eds. Increasing Returns and Economic Analysis, London, Macmillan.

Williamson, Jeffrey (1998), "Globalization, Labor Markets and Policy Backlash in the Past," Journal of Economic Perspectives, 12, 51-72.

Yang, X. (1991), "Development, Structure Change, and Urbanization," Journal of Development Economics, 34: 199222.

Yang, Xiaokai (1994), "Endogenous vs. Exogenous Comparative Advantages and Economies of Specialization vs. Economies of Scale," Journal of Economics, 60, 29-54.

Yang, X. and Borland, J. (1991): "A Microeconomic Mechanism for Economic Growth". Journal of Political Economy, 99: 460-82.

Yang, Xiaokai and Ng, Siang (1998), "Specialization and Division of Labor: A Survey," in K. Arrow, Y-K Ng and $\mathrm{X}$, Yang eds. Increasing returns and Economics Analysis, London, Macmillan.

Yang, X., Wang, J., and Wills, I. (1992), "Economic Growth, Commercialization, and Institutional Changes in Rural China, 1979-1987", China Economic Review, 3, 1-37.

Young, Allyn (1928), "Increasing Returns and Economic Progress", The Economic Journal, 38, 527-42.

Zhou, Lin, Guangzhen Sun, and Xiaokai Yang (1998), "General Equilibria in Large Economies with Endogenous Structure of Division of Labor," Working Paper, Department of Economics, Monash University. 